\title{
Transmission of Tetracapsuloides bryosalmonae (Myxozoa: Malacosporea) to Fredericella sultana (Bryozoa: Phylactolaemata) by various fish species
}

\author{
Daniel S. Grabner, Mansour El-Matbouli ${ }^{*}$ \\ Clinic for Fish and Reptiles (formerly: Institute of Zoology, Fish Biology and Fish Diseases), University of Munich, \\ Kaulbachstr. 37, 80539 Munich, Germany
}

\begin{abstract}
Tetracapsuloides bryosalmonae is a myxozoan parasite of salmonids and freshwater bryozoans, which causes proliferative kidney disease (PKD) in the fish host. To test which fish species are able to transmit $T$. bryosalmonae to bryozoans, an infection experiment was conducted with 5 PKD-sensitive fish species from different genera. Rainbow trout Oncorhynchus mykiss, brown trout Salmo trutta, brook trout Salvelinus fontinalis, grayling Thymallus thymallus and northern pike Esox lucius were cohabitated with T. bryosalmonae-infected Fredericella sultana colonies and then subsequently cohabitated with statoblast-reared parasite free Bryozoa. Statoblasts from infected colonies were tested by PCR to detect cryptic stages of T. bryosalmonae, which may indicate vertical transmission of the parasite. In this study, brown trout and brook trout were able to infect Bryozoa, while there was no evidence that rainbow trout and grayling were able to do so. Few interstitial kidney stages of the parasite were detected by immunohistochemistry in brown trout and brook trout, while rainbow trout and grayling showed marked proliferation of renal interstitial tissue and macrophages with numerous parasite cells. Intraluminal stages in the kidney tubules were only detected in brown trout and rainbow trout. In contrast to previous observations, pike was not susceptible to PKD in these trials according to the results of $T$. bryosalmonae-specific PCR. No DNA of T. bryosalmonae was detected in any statoblast.
\end{abstract}

KEY WORDS: Tetracapsuloides bryosalmonae $\cdot$ Myxozoa $\cdot$ Malacosporea $\cdot$ Bryozoa $\cdot$ Proliferative kidney disease $\cdot \mathrm{PKD} \cdot$ Host specificity $\cdot$ Transmission experiment

\section{INTRODUCTION}

Proliferative kidney disease (PKD) is an important disease of both farmed and wild salmonid fish in Europe and North America that can cause large economic losses and endanger wild fish populations (Hedrick et al. 1993, Wahli et al. 2002). It is caused by the myxozoan parasite Tetracapsuloides bryosalmonae (Myxozoa: Malacosporea), whose life cycle involves different species of freshwater Bryozoa as invertebrate hosts (Anderson et al. 1999). Fish are infected via spores released from infected bryozoan colonies (Feist et al. 2001) and the parasite develops in the kidney interstitium and tubule lumina, where new spores are formed (Kent \& Hedrick 1985). These spores are probably released via the urine to the water where they presumably again infect bryozoan colonies (Hedrick et al. 2004). Most salmonid species are susceptible to PKD (Hedrick et al. 1993) and one non-salmonid, northern pike (Esox lucius), has been reported to show myxozoan stages that resemble those from histological sections of PKD-infected trout (Seagrave et al. 1981, Bucke et al. 1991). These parasite stages could be stained with monoclonal antibodies raised against $T$. bryosalmonae antigens (Morris et al. 2000).

Experimental transmission of Tetracapsuloides bryosalmonae from fish to Bryozoa has been problematic. While Morris \& Adams (2006) successfully transmitted 
the parasite using brown trout Salmo trutta, in the study of Tops et al. (2004), no infection of Bryozoa could be achieved with PKD-infected brown trout, rainbow trout Oncorhynchus mykiss or chinook salmon O. tschawytscha. It remains unknown in which fish host species $T$. bryosalmonae can form mature spores infective for Bryozoa. In the present study, different fish species were tested for the first time under laboratory conditions for their susceptibility to PKD and their subsequent capability to transmit T. bryosalmonae back to Bryozoa. We also took into account the possibility that the presence of cryptic parasite stages in bryozoan statoblasts could cause an overt infection when colonies start to grow.

\section{MATERIALS AND METHODS}

Fish. Rainbow trout of the American Trout Lodge strain were raised from eggs in our specific pathogenic free (SPF) wet lab. Brown trout, brook trout and grayling were obtained as SPF fingerlings from 2 Bavarian hatcheries. Pike (10 to $15 \mathrm{~cm}$ ) were obtained from a Bavarian hatchery. All fish were young of the year. Fish were maintained in aquaria with flowthrough dechlorinated tap water and fed on commercially available fish food or live fish (pike only) until they reached a size of 9 to $15 \mathrm{~cm}$.

Bryozoa. Infected bryozoan colonies were collected from the field at the river Lohr, near Lohr am Main, Germany. Colonies were found attached to alder roots reaching into the water between about the 20 and $100 \mathrm{~cm}$ depths. In the lab, root parts $(5$ to $10 \mathrm{~cm}$ length, 0.2 to $1.5 \mathrm{~cm}$ diameter) harbouring bryozoan colonies were attached with cyanoacrylate adhesive (Loctite 401 Instant Adhesive, Loctite) to $12 \mathrm{~cm}$ plastic petri dishes and were cultured according to Morris et al. (2002). They were fed daily with a diet containing 5 live algae species (Cryptomonas sp., Chlamydomonas sp., Synechococcus sp., Phacotus sp. and Fragilaria sp.). Each algae species was kept as a pure culture. For one 151 container with 5 petri dishes with bryozoan colonies approximately $20 \mathrm{ml}$ of each algae species was used for feeding. Additionally, autoclaved mud from a fish pond was used as sediment-containing organic material in the culture containers to increase the growth of bacteria and protozoa associated with the Bryozoa. These organisms served as additional food for the Bryozoa. The temperature in the containers was kept between 15 and $18^{\circ} \mathrm{C}$ and water was changed weekly. According to colony and statoblast morphology, the collected Bryozoa were identified as Fredericella sultana (Bryozoa: Phylactolaemata) using the key of Wood \& Okamura (2005). Infection of the colonies was confirmed by observing developmental stages of Tetracapsuloides bryosalmonae within the bryozoan metacoel with a dissection microscope.

As Fredericella sultana does not produce free floatoblasts like most other freshwater Bryozoa, statoblasts were freed by dissecting the chitinous tubes of dead bryozoan colony remnants and removing the statoblasts with fine needles and forceps. Statoblasts were collected with a pipette and were either frozen at $-20^{\circ} \mathrm{C}$ for later DNA extraction or stored in tap water for 1 to $2 \mathrm{wk}$ at $4^{\circ} \mathrm{C}$ before 5 to 15 statoblasts were transferred to a petri dish filled with tap water. Dishes were stored at about $20^{\circ} \mathrm{C}$ until the statoblasts stuck to the surface and Bryozoa started to hatch. After that, the dishes were placed inverted into a culture container (described above) to allow further growth of the colonies. Second-generation statoblasts were obtained from these F. sultana colonies, raised in the same manner and used for the infection trials.

Test of statoblasts for cryptic parasite stages. To determine whether Tetracapsuloides bryosalmonae is transmitted vertically by dormant parasite stages in statoblasts, DNA was extracted from statoblasts obtained from PKD-infected and uninfected (secondgeneration, laboratory-raised) bryozoan colonies for amplification with the T. bryosalmonae specific PCR. Four samples consisting of 20 statoblasts each were used for extraction from both groups. Each of the 4 samples from uninfected and infected bryozoan colonies was collected from one petri dish. Before extraction, statoblasts were washed with 4 changes of distilled water and vortexing. Finally, wash water was removed with a pipette and statoblasts were stored at $-20^{\circ} \mathrm{C}$ until DNA extraction.

Infection trials with PKD-susceptible fish. Four rainbow trout, 4 brown trout and 4 brook trout were all cohabitated with infected bryozoan colonies containing numerous parasite stages, in one $50 \mathrm{l}$ aquarium with minimal flow-through water at $15^{\circ} \mathrm{C}$ for $2 \mathrm{wk}$. During this time, the colonies were fed daily by adding about $20 \mathrm{ml}$ of each algae species to the aquarium. Subsequently, the fish were separated by species and placed in $20 \mathrm{l}$ aquaria with flow-through water adjusted to $15 \pm 1^{\circ} \mathrm{C}$ during the whole experiment. Three weeks after the start of cohabitation, one specimen from each group was killed and a sample of the kidney was frozen at $-20^{\circ} \mathrm{C}$ for analysis by Tetracapsuloides bryosalmonae-specific PCR. Eight weeks after infection of the fish, 2 petri dishes with a minimum of 3 Fredericella sultana colonies (obtained from statoblasts and grown for 3 mo after hatching) comprising 10 or more individual zooids were kept in each fish aquarium for $8 \mathrm{~h}$ per day. For the remaining time the dishes were transferred back to separate culture containers for feeding. About $14 \mathrm{wk}$ after the beginning of the experiment, 1 fish of each group was killed and 
samples of the kidney were dissected and frozen for PCR, or fixed for light microscopy. Five dishes with several statoblast-raised colonies each, which were cultured without contact to fish, served as negative control for these experiments. After exposure to the fish, all bryozoan colonies were examined under a dissection microscope every second day for 6 mo for developmental stages of $T$. bryosalmonae. The unexposed colonies were visually observed for an additional 7 mo to check for a possible outbreak of $T$. bryosalmonae derived from cryptic stages in statoblasts. As graylings were not available at the same time as the other species, they were tested for spore production with the same experimental setup in a second experiment 3 mo later.

Infection trials with northern pike. To test the susceptibility of pike, 4 fish were exposed as described above and kidney samples were prepared for PCR $4 \mathrm{wk}$ after the beginning of cohabitation with infected Bryozoa. As these fish were not SPF, kidney samples were also taken from 4 uninfected individuals to test for background infection.

DNA extraction and PCR. Statoblasts or tissues were homogenized with micropestles (Eppendorf) in a $1.5 \mathrm{ml}$ PCR tube and extraction was performed with a QIAamp ${ }^{\circledR}$ DNA Mini Kit (Qiagen), according to manufacturer's instructions. DNA from 20 statoblasts, a part of a bryozoan colony (comprising 15 individual zooids) or $25 \mathrm{mg}$ of kidney were each eluted in $50 \mu \mathrm{l}$ elution buffer. The DNA from the bryozoan colony served as a positive control. Because the applied extraction method was, according to our knowledge, never used for bryozoan statoblasts, the success of DNA extraction was tested by PCR amplification with a Bryozoa-specific primer-pair (bryo18S-F 5'-CTC TAG GCT GGC GGT CC-3' and bryo18S-R 5'-CGA CCG TCG GAG ATC GGT-3'), which was designed to amplify a $730 \mathrm{bp}$ fragment of the SSU rRNA gene sequence of Fredericella sultana obtained from the GenBank (accession number: DQ221751). To exclude any unspecific amplification of DNA from other species, the primers were tested by the BLAST algorithm (National Center for Biotechnology Information, www.ncbi.nlm.nih.gov/ BLAST) for homologies with SSU DNA sequences in the database. Additionally, a sample of invertebrates (mostly fly larvae), bacteria and protists from the petri dishes in the bryozoan culture and 1 obtained by centrifugation of the culture medium was used for DNA extraction and tested with the F. sultana SSU-primers. One $20 \mu \mathrm{l}$ PCR mix contained $10 \mu \mathrm{l} 2 \times$ ReddyMix PCR Master Mix (ABGene), $0.35 \mu \mathrm{mol}$ of each primer, $1 \mu \mathrm{l}$ DNA and distilled water. The reaction-mix was topped up to $20 \mu \mathrm{l}$ with distilled water. The following program was used: $94^{\circ} \mathrm{C}$ for $4 \mathrm{~min}, 35$ cycles of $94^{\circ} \mathrm{C}$ for $1 \mathrm{~min}$, $58^{\circ} \mathrm{C}$ for $1 \mathrm{~min}, 70^{\circ} \mathrm{C}$ for $70 \mathrm{~s}$ and a final elongation step at $70^{\circ} \mathrm{C}$ for $5 \mathrm{~min}$. The presence of Tetracapsuloides bryosalmonae DNA in the samples was tested with the primer-pair 5F and 6R according to Kent et al. (1998). All PCR amplifications were carried out on an Eppendorf Mastercycler.

Histology and immunohistochemistry. Samples for light microscopy were fixed in $10 \%$ neutral buffered formalin, washed, dehydrated and embedded in paraffin wax (Tissue-Tek VIP, Sakura Bayer Diagnostics). Sections were cut at $5 \mu \mathrm{m}$ (1140 Autocut, ReichertJung) and either stained with haematoxylin and eosin or processed for immunohistochemistry. For immunohistochemical staining, the monoclonal antibody P01 (Aquatic Diagnostics) was used, according to the manufacturer's instructions, and sections were counterstained with haematoxylin. A kidney sample of a SPFinfected rainbow trout was used as control.

\section{RESULTS}

\section{Test of statoblasts for cryptic parasite stages}

Both the statoblasts from infected and uninfected bryozoan colonies were found negative for Tetracapsuloides bryosalmonae infection by PCR. The DNA extraction was shown to be successful with the protocol used, as the amplification with the Bryozoa-specific $18 \mathrm{~S}$ primer pair (bryo $18 \mathrm{~S}-\mathrm{F}$ and bryo $18 \mathrm{~S}-\mathrm{R}$ ) gave the expected $730 \mathrm{bp}$ band for all statoblast samples and a part of a bryozoan colony used as positive control. No amplicon was obtained with DNA from other organisms in the culture medium.

\section{Fish infection}

The kidney samples from brown trout, brook trout, rainbow trout and grayling tested by PCR 3 and $14 \mathrm{wk}$ post initial exposure (PE) to infected Bryozoa were PKD-positive. Therefore, it could be assumed that the infection was successful and that the fish did not recover from the infection during the cohabitation trials. No external or internal PKD-related symptoms were observed in the fish dissected $3 \mathrm{wk}$ PE. Of the fish sampled 14 wk PE, only rainbow trout showed clinical signs of PKD, such as swelling of the body cavity and slight exophthalmos (from $5 \mathrm{wk}$ PE). None of the other fish species showed any external clinical signs. Heavy internal signs of disease (swollen kidney and spleen) were detected in rainbow trout and grayling, while brown trout and brook trout showed only minor kidney swelling. Neither the Bryozoa-exposed or unexposed pike kidney samples tested positive for Tetracapsuloides bryosalmonae by PCR. 

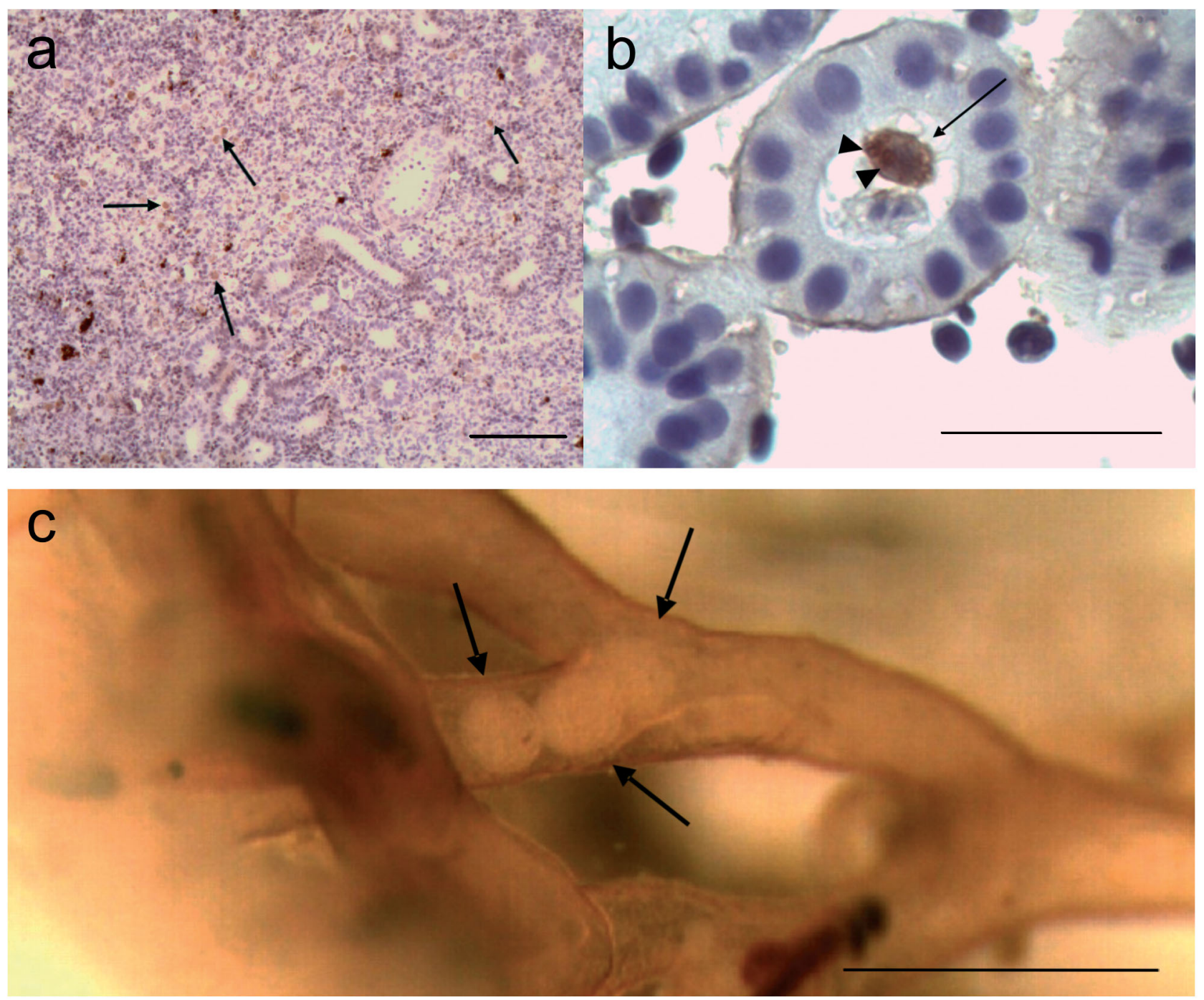

Fig. 1. (a) Paraffin section of rainbow trout kidney. Proliferation of kidney interstitial tissue and numerous stages of Tetracapsuloides bryosalmonae (arrows) can be seen. Stained with P01-antibody and haematoxylin. Scale bar = $100 \mu \mathrm{m}$. (b) Paraffin section of brown trout kidney. Intraluminal parasites are stained with the P01-antibody (arrows). Forming polar capsules can be seen (arrowheads). Counter-stained with haematoxylin. Scale bar $=25 \mu \mathrm{m}$. (c) Laboratory-infected Fredericella sultana colony. Sac stages of $T$. bryosalmonae (arrows) can be seen in the bryozoan metacoel. Scale bar $=0.5 \mu \mathrm{m}$

\section{Histology and immunohistochemistry}

Kidney sections of rainbow trout showed a high density of interstitial parasite stages and a proliferation of interstitial tissue (Fig. 1a). Similar but less pronounced development was seen in the kidney sections of grayling. Almost no proliferation of the kidney interstitium was observed in brook trout and brown trout in the kidney sections investigated, and interstitial parasite stages detected by immunohistochemistry were rare compared with rainbow trout. Luminal stages could be detected with the P01-antibody in brown trout and rainbow trout, but not in kidney sections of brook trout and grayling. Maturing spores with polar capsules were exclusively observed in the lumen of kidney tubules of brown trout (Fig. 1b).

\section{Infection of Bryozoa}

Four weeks PE to infected brook trout, Bryozoa showed typical Tetracapsuloides bryosalmonae sac stages (McGurk et al. 2006) in a small part of the colony (Fig. 1c). One week later, the first aggregations of presaccular cells could be observed in the body cavity of bryozoans exposed to brown trout. Within the following $3 \mathrm{wk}$, more colony parts showed overt infection, with maturing sac stages and spores floating in the 
metacoel. After 1 mo, almost all bryozoan colonies that had been exposed to brown trout showed overt infections. The prevalence of infection in brook troutexposed colonies was lower, but a direct comparison was impossible due to considerable differences in colony size. Bryozoa cohabitated with infected rainbow trout and grayling showed no visible $T$. bryosalmonae stages at any time up to the end of the experiment, 6 mo PE. No macroscopically visible parasite development was observed in unexposed control bryozoan colonies during the 13 mo of observation.

\section{DISCUSSION}

Transmission of cryptic PKD stages via bryozoan statoblasts was already considered due to the apparently incomplete sporogenesis and the intense immune response in fish hosts (see discussion by Tops et al. 2004). In the present study, no parasite DNA could be detected in Fredericella sultana statoblasts from infected colonies and no parasite stages could be observed in colonies raised from these statoblasts after more than 1 yr. It might nevertheless be possible that dormant stages in bryozoan statoblasts may occur in some cases, for example, Tetracapsuloides bryosalmonae-susceptible bryozoan species like Plumatella repens may incorporate stages of $T$. bryosalmonae into their statoblasts more frequently. Taticchi et al. (2004) observed vermiform stages similar to the vermiform stage of Buddenbrockia plumatellae (Myxozoa: Malacosporea) leaving $\mathrm{KOH}$-treated statoblasts of Plumatella fungosa. In their work, it could not be determined to which systematic group these worms belonged, but this finding might be evidence for malacosporean stages in bryozoan statoblasts. Another explanation for the lack of dormant stages in the statoblasts used in the present study could be that incorporation of stages into statoblasts is restricted to some strains of F. sultana or T. bryosalmonae and might reflect adaptation to habitats with only few or no fish hosts.

We demonstrated the ability of 2 fish species, brown trout and brook trout, to transmit Tetracapsuloides bryosalmonae to Fredericella sultana. PKD-infected brown trout were shown by Morris \& Adams (2006) to transmit the parasite to $F$. sultana when the bryozoan culture was exposed to outflow from a tank with infected fish. In their study, the timeline of the life cycle, from the infection of the fish to the first observable stages in the bryozoan colonies, was similar to our results. This indicates that the life cycle of $T$. bryosalmonae can be reliably reproduced in the laboratory. Additionally, we showed that PKD-infected brook trout are capable of infecting Bryozoa and we assume that this species could serve as host for $T$. bryosalmonae under natural conditions. Arctic charr Salvelinus alpinus is susceptible to PKD as well and the parasite forms numerous intraluminal sporogonic stages in this species (Kent et al. 2000). We suggest that other species of Salvelinus might also be able to transmit PKD to bryozoans.

The finding that rainbow trout infected with Tetracapsuloides bryosalmonae were unable to infect bryozoans in this experiment provides evidence for possible strain differences between parasites and/or hosts from the USA and Europe, as already discussed by Morris \& Adams (2006). Hedrick et al. (2004) remarked that both number of maturing spores and prevalence of spores in the urine of rainbow trout used in their study were low, and in the following year no spores could be observed at all. Therefore, if the formation of spores is a rare event in rainbow trout, the 3 fish that were cohabitated with Bryozoa in the present study might not have been enough to infect bryozoan colonies. Comparatively mild disease symptoms are typical for most myxozoans in their natural hosts (Lom \& Dyková 1992, 1995). Hence the mild kidney swelling and proliferation of interstitial tissue indicate that brown trout is the original host for T. bryosalmonae in Europe. In contrast, rainbow trout are less well-adapted, at least to the European strain of the parasite, showing severe symptoms and high mortalities. Bucke et al. (1991) also reported lesssevere symptoms in brown trout than in rainbow trout infected by $T$. bryosalmonae in a PKD-endemic fish farm. The present study indicates that it is unlikely that these different host responses can be attributed to different dosages of $T$. bryosalmonae spores, as all fish species except grayling and pike were infected together in 1 aquarium at the same time. Furthermore, even very low spore numbers per fish can cause heavy clinical signs of PKD in rainbow trout (McGurk et al. 2006).

The low abundance of interstitial stages we observed in the kidneys of brook trout and brown trout might indicate that these fish were recovering from the disease. A similar observation was made by Clifton-Hadley \& Feist (1989), who found few or no interstitial PKD stages in brown trout $10 \mathrm{wk}$ or later after exposure to spores of $T$. bryosalmonae or intraperitoneal injection of developmental stages from homogenised kidney. In the same study, intraluminal stages were also found only in brown trout and not in rainbow trout. Intraluminal sporogonic stages can be present for a long time after the clinical signs of the infection have disappeared (Kent \& Hedrick 1986); this seemed to be the case at least for the brown trout during this experiment, where developing sporogonic stages with maturing polar capsules and only few interstitial parasites were seen in histological sections 
of kidney samples from 14 wk PE. Feist \& Bucke (1993) found no interstitial PKD stages in experimentally infected brook trout, but in contrast to the present study, luminal stages were present in this species. The fact that no intraluminal parasitic stages were found in brook trout kidney might be due to the low number of sporogonic stages in this species, or indicate recovery with almost complete elimination of the parasite from the kidney tubules. It is also possible that only the single fish sampled for the histological observations did not show intraluminal parasitic stages because of individual variation in infection severity and progress.

The PKD-infected grayling used in this experiment could not transmit the infection to Bryozoa. The fact that these fish showed similar proliferation of kidney interstitial tissue as in rainbow trout might indicate that they are a host to which the parasite is not adapted. The parasite might be somehow prevented from entering the kidney tubules efficiently, which could lead to an intensified multiplication of the parasite in the kidney interstitium. These results are contradictory to the findings of Bucke et al. (1991), Feist \& Bucke (1993) and Morris et al. (2000), all of whom observed intratubular stages in PDK-infected grayling. It is possible that the parasite requires more time to form spores in grayling than was provided in the course of this experiment, yet bryozoans were cohabitated with the fish for 6 mo and it is unlikely that formation of sporogonic-stages in grayling takes so much longer than in brown trout. Host and parasite strain differences or the low sample size may also be responsible for the different findings in the present work and the results of previous studies.

A constraint of this study is that the bryozoan colonies from the rainbow-trout-and-grayling group were not tested by PCR at the end of the experimentalthough it seems unlikely that cryptic PKD stages did not cause an overt infection in Bryozoa cohabitated with rainbow trout or grayling, as they were kept under the same conditions as the brown- and brooktrout-exposed colonies.

As northern pike did not become infected, or at least did not show any kidney stages after cohabitation with PKD-infected Fredericella sultana colonies, it is doubtful that this species is susceptible to Tetracapsuloides bryosalmonae. The myxozoan-like stages found in pike (Seagrave et al. 1981, Bucke et al. 1991, Morris et al. 2000) might be stages of other malacosporeans such as Buddenbrockia spp., of which 2 are described to date as parasites of bryozoans (Schröder 1910, Canning et al. 2007); but no fish host has been identified yet for these malacosporeans. Morris et al. (2000) used 4 monoclonal antibodies raised against $T$. bryosalmonae antigens and demonstrated reaction with stages in pike kidney. This supports the hypothesis that the pike parasite is related to the Malacosporea.

Further investigations of different parasite strains and their capability to infect different fish species are clearly warranted to clarify the entire host spectrum of Tetracapsuloides bryosalmonae and different (genetic) adaptations of the parasite to the regionally available host species.

Acknowledgements. The authors thank A. Adams and D. J. Morris for the help and exchange of information about culturing of bryozoans. This work was supported by the German Science Foundation (DFG), Grant Number EL 174/5-1.

\section{LITERATURE CITED}

Anderson CL, Canning EU, Okamura B (1999) Molecular data implicate bryozoans as hosts for PKX (Phylum Myxozoa) and identify a clade of bryozoan parasites within the Myxozoa. Parasitology 119:555-561

Bucke D, Feist SW, Clifton-Hadley RS (1991) The occurrence of proliferative kidney disease (PKD) in cultured and wild fish: further investigations. J Fish Dis 14:583-588

Canning EU, Curry A, Hill SLL, Okamura B (2007) Ultrastructure of Buddenbrockia allmani n. sp. (Myxozoa, Malacosporea), a parasite of Lophopus crystallinus (Bryozoa, Phylactolaemata). J Eukaryot Microbiol 54:247-262

Clifton-Hadley RS, Feist SW (1989) Proliferative kidney disease in brown trout Salmo trutta: further evidence of a myxosporean aetiology. Dis Aquat Org 6:99-103

$>$ Feist SW, Bucke D (1993) Proliferative kidney disease in wild salmonids. Fish Res 17:51-58

Feist SW, Longshaw M, Canning EU, Okamura B (2001) Induction of proliferative kidney disease (PKD) in rainbow trout Oncorhynchus mykiss via the bryozoan Fredericella sultana infected with Tetracapsula bryosalmonae. Dis Aquat Org 45:61-68

Hedrick RP, MacConnell E, de Kinkelin P (1993) Proliferative kidney disease of salmonid fish. Annu Rev Fish Dis 3: $277-290$

Hedrick RP, Baxa DV, de Kinkelin P, Okamura B (2004) Malacosporean-like spores in urine of rainbow trout react with antibody and DNA probes to Tetracapsuloides bryosalmonae. Parasitol Res 92:81-88

Kent ML, Hedrick RP (1985) PKX, the causative agent of proliferative kidney disease (PKD) in Pacific salmonid fishes and its affinities with the Myxozoa. J Protozool 32:254-260

Kent ML, Hedrick RP (1986) Development of the PKX myxosporean in rainbow trout Salmo gairdneri. Dis Aquat Org $1: 169-182$

Kent ML, Khattra J, Hervio DML, Devlin RH (1998) Ribosomal DNA sequence analysis of isolates of the PKX Myxosporean and their relationship to members of the genus Sphaerospora. J Aquat Anim Health 10:12-21

Kent ML, Khattra J, Hedrick RP, Devlin RH (2000) Tetracapsula renicola $\mathrm{n}$. sp. (Myxozoa: Saccosporidae); the PKX Myxozoan - the cause of proliferative kidney disease of salmonid fishes. J Parasitol 86:103-111

Lom J, Dyková I (1992) Myxosporidia (Phylum Myxozoa). In: Lom J, Dyková I (eds) Protozoan parasites of fish. Development in aquaculture and fisheries science, Vol 26. Elsevier, Amsterdam, p 159-235

Lom J, Dyková I (1995) Myxosporea (Phylum Myxozoa). In: 
Woo PTK (ed) Protozoan and metazoan infections. CAB International, Wallingford, p 97-148

McGurk C, Morris DJ, Auchinachie NA, Adams A (2006) Development of Tetracapsuloides bryosalmonae (Myxozoa: Malacosporea) in bryozoan hosts (as examined by light microscopy) and quantitation of infective dose to rainbow trout (Oncorhynchus mykiss). Vet Parasitol 135: 249-257

$>$ Morris DJ, Adams A (2006) Transmission of Tetracapsuloides bryosalmonae (Myxozoa: Malacosporea), the causative organism of salmonid proliferative kidney disease, to the freshwater bryozoan Fredericella sultana. Parasitology 133:701-709

Morris DJ, Adams A, Feist SW, McGeorge J, Richards RH (2000) Immunohistochemical and PCR studies of wild fish for Tetracapsula bryosalmonae (PKX), the causative organism of proliferative kidney disease. J Fish Dis 23: 129-135

Morris DJ, Morris DC, Adams A (2002) Development and release of a malacosporean (Myxozoa) from Plumatella repens (Bryozoa: Phylactolaemata). Folia Parasitol 49:25-34

Editorial responsibility: Otto Kinne,

Oldendorf/Luhe, Germany
Schröder O (1910) Buddenbrockia plumatellae, eine neue Mesozoenart aus Plumatella repens L. und Pl. fungosa Pall. Zeit Wiss Zool 96:525-537

Seagrave CP, Bucke D, Hudson EB, McGregor D (1981) A survey of the prevalence and distribution of proliferative kidney disease (PKD) in England and Wales. J Fish Dis 4:437-439

Taticchi MI, Gustinelli A, Fioravanti ML, Caffara M, Pieroni G, Prearo M (2004) Is the worm-like organism found in the statoblasts of Plumatella fungosa (Bryozoa, Phylactolaemata) the vermiform phase of Tetracapsuloides bryosalmonae (Myxozoa, Malacosporea)? Ital J Zool 71:143-146

Tops S, Baxa DV, McDowell TS, Hedrick RP, Okamura B (2004) Evaluation of malacosporean life cycles through transmission studies. Dis Aquat Org 60:109-121

Wahli T, Knuessel R, Bernet D, Segner H and others (2002) Proliferative kidney disease in Switzerland: current state of knowledge. J Fish Dis 25:491-500

Wood TS, Okamura B (2005) A new key to the freshwater bryozoans of Britain, Ireland and continental Europe, with notes on their ecology. Scientific Publication No. 63, Freshwater Biology Association, Ambleside

Submitted: November 27, 2007; Accepted: January 11, 2008 Proofs received from author(s): March 14, 2008 